\title{
REVIEW
}

\section{Adult-onset asthma: is it really different?}

\author{
Selma B. de Nijs, Lisette N. Venekamp and Elisabeth H. Bel
}

\begin{abstract}
Asthma that starts in adulthood differs from childhood-onset asthma in that it is often non-atopic, more severe and associated with a faster decline in lung function.

Understanding of the underlying mechanism of adult-onset asthma and identification of specific phenotypes may further our understanding of pathophysiology and treatment response, leading to better targeting of both existing and new approaches for personalised management. Pivotal studies in past years have led to sustained progress in many areas, ranging from risk factors for development, identification of different phenotypes, and introduction of new therapies.

This review highlights and discusses literature on adult-onset asthma, with special focus on the differences from childhood-onset asthma, risk factors for development, phenotypes of adultonset asthma and new approaches for personalised management.
\end{abstract}

KEYWORDS: Adult onset, asthma, childhood onset, phenotypes, risk factors, treatment

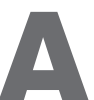
sthma is a heterogeneous disorder, in which age of onset seems to play an important role. Although the vast majority of asthma publications in the literature are about allergic asthma starting in childhood, the incidence among adults is as high as 12 cases per 1,000 person-years $[1,2]$. Recently, clustering methods to group together patients with similar clinical characteristics led to the identification of different asthma phenotypes [3, 4]. In the Severe Asthma Research Program, for example, five clusters were identified using 34 clinical variables [4]. $80 \%$ of the subjects could be assigned to a cluster using only three variables: baseline forced expiratory volume in $1 \mathrm{~s}$ (FEV1) (before bronchodilation); maximum FEV1 after bronchodilation; and age of onset of asthma [4]. One of these phenotypes (cluster 3), consisting exclusively of patients with adult-onset asthma, was characterised by a preponderance of obese females, but also, the most severe asthma phenotype (cluster 5), consisted mainly of patients with adult onset disease. This was the cluster with the most severe airflow limitation at baseline and residual airflow limitation after bronchodilation. This finding fits with earlier observations that adult-onset asthma is associated with a more rapid decline in lung function [5, 6]. However, despite ample evidence that asthma can develop in patients who never had any relevant respiratory symptoms as a child, there still exists some controversy about the existence of adult onset asthma as a separate entity [7].

This narrative review focuses on asthma that starts in adulthood and provides an overview of recent studies regarding differences between childhood-onset asthma, risk factors for development, different phenotypes and new approaches for personalised management.

\section{HISTORICAL PERSPECTIVE}

More than half a century ago, adult-onset asthma was already recognised as a separate subtype of asthma by several renowned physicians. It started in 1940 when RACKEMANN [8] distinguished "extrinsic" or allergic asthma from "intrinsic" or nonallergic asthma. He noticed that patients with intrinsic asthma typically had a late onset and a more severe clinical course of the disease than patients with extrinsic asthma. In addition, females were more often affected and symptoms often started following a respiratory infection. The terminology "extrinsic" and "intrinsic" asthma was replaced by "allergic" and "nonallergic" asthma in an official European Academy of Allergy and Clinical Immunology position statement in 2001 [9]. Although several studies could not find convincing differences between allergic and nonallergic asthma regarding inflammation [10], the clinical phenotypes of allergic and nonallergic asthma were found to be highly distinct [11]. In 2004, instead of reintroducing the term "intrinsic" asthma, MiRANDA et al. [12] suggested differentiating asthma on the basis of age at onset (early versus late onset) and presence of airway eosinophilia. Interestingly, adult-onset eosinophilic asthma was also identified as a separate asthma phenotype in a large asthma cohort in the UK in 2008 [3]. Thus, the differentiation between
AFFILIATIONS

Dept of Respiratory Medicine, Academic Medical Centre and University of Amsterdam, Amsterdam, The Netherlands.

CORRESPONDENCE

S.B. de Nijs

Dept of Respiratory Medicine, F5-260

Academic Medical Centre

1100 DD Amsterdam

the Netherlands

E-mail: S.B.deNijs@amc.uva.n

Received:

Nov 282012

Accepted after revision:

Dec 172012

PROVENANCE

Submitted article, peer reviewed. 
childhood-onset asthma and adult-onset asthma is not new, and now that the importance of phenotyping of asthma is increasingly recognised, adult-onset asthma seems to have been "rediscovered".

\section{CHILDHOOD-ONSET ASTHMA}

Before discussing adult-onset asthma in more detail, we will briefly discuss childhood-onset asthma. The vast majority of asthma starts in early childhood. About $95 \%$ of asthma patients have their first episode before the age of 6 years [2]. Young males are consistently reported to have more prevalent wheeze and asthma than young females [13]. However, at the age of 11 years, the prevalence of asthma in young males $(7.7 \%)$ and young females $(7.4 \%)$ is similar and after 16 years of age the disease is more common in females (6.2\%) than in males (4.3\%) [14].

The main risk factors associated with childhood-onset asthma are genetic predisposition, and a family history of allergy and asthma, viral respiratory infections, bacterial colonisation, allergic sensitisation and tobacco exposure [15].

A parental history of atopic diseases has been long recognised to be a strong risk factor for asthma in children [16]. Although genetic studies have showed that asthma is genetically heterogeneous, genome-wide association studies have identified a novel region containing ORMDL3 at chromosome 17q21 that is strongly associated with childhood-onset asthma and significantly linked to ORMDL3 transcript abundance [17]. These results have been successfully replicated in other childhood-onset asthma cohorts [18]. Thus, genetic predisposition seems to play a major role in the onset of asthma in early childhood.

Large, prospective follow-up studies have shown that early and persistent sensitisations to perennial allergens are a strong risk factor for asthma in childhood [19]. Furthermore, childhood-onset asthma is typically associated with other atopic diseases, including allergic rhinitis and atopic dermatitis [20]. Even at adult age the amounts of total and specific immunoglobulin (Ig)E are higher in childhood-onset asthma than in adult-onset asthma [12]. Thus, atopy and allergy seem to be closely linked to asthma starting in childhood.

Viral infections are another risk factor for developing early childhood asthma [21]. Long-term follow-up studies have shown that wheezy episodes associated with rhinovirus infection are a strong predictor of asthma by the age of 6 years $[22,23]$. However, studies have also reported that children with early wheezy symptoms and a predisposition to asthma and atopy are at increased risk of lower respiratory infection [24-26]. Therefore, the direction of causality of viral infection and the development of asthma is still unclear.

Bacterial colonisation may play a role in the development of childhood-onset asthma. A study showed that neonates colonised in the hypopharyngeal region with Streptococcus pneumoniae, Haemophilus influenzae or Moraxella catarrhalis, or with a combination of these organisms, are at increased risk for recurrent wheeze and asthma early in life [27]. Of interest, some aspects in early life appear to protect against the development of asthma. In children, contact with livestock and being born and raised on a farm reduces the risk of asthma in adulthood [28-30]. Similar to viruses, it is unknown whether the bacterial colonisation acts as the environmental trigger in genetically predisposed persons or whether this colonisation is merely a marker of the underlying genetic asthmatic constitution.

Pre-natal and post-natal smoke exposure has been linked to asthma and other wheezy disorders, particularly in the first years of life [31]. Also, exposure to traffic-related air pollution may cause asthma in children [32].

With respect to response to treatment, daily inhaled corticosteroids are highly effective in improving asthma control in childhood-onset allergic asthma as demonstrated by one systematic review [33] and another meta-analysis [34]. However, the effect of inhaled corticosteroids is less evident among children with recurrent wheezy episodes not diagnosed as asthma [34].

Taken together, childhood-onset asthma typically runs in families, is associated with allergy in most patients, and has a good prognosis with a satisfactory response to medical treatment. The role of bacteria and viruses in childhood-onset asthma is still unclear.

\section{ADULT-ONSET ASTHMA}

Adult-onset, or late-onset, asthma is considered when asthma symptoms represent for the first time during adulthood. Several definitions of adult-onset asthma can be found in the literature. The age at diagnosis determining the term late-onset asthma varies from 12 years of age [12] to $\geqslant 65$ years of age [35]. Most studies about asthmatic symptoms earlier in life are based on questionnaires. The possibility of recall bias is a frequently made comment [7]. For example, in the Tucson study, a relationship was found between asthma manifesting at age 40 years and persistent wheezing at age 6 years (presumably long forgotten about by the family) [36]. However, a study performed by TOREN et al. [37] showed that the reported age of asthma onset in adults is quite accurate.

In contrast to childhood-onset asthma, less is known about the prevalence and factors associated with adult-onset asthma. Studies have shown that it mainly effects females [8], has a low remission rate [38] and is less often associated with allergy and atopic diseases [39]. In addition, many patients with adultonset asthma have a poor prognosis [38], with a faster decline in lung function $[6,40]$ and more severe persistent airflow limitation [41]. New-onset adult severe asthmatics have compromised lung function even if they have asthma of short duration [42], suggesting that significant loss of lung function occurs at or soon after the initial diagnosis. Still, adult-onset asthma is largely under investigated and far from completely understood.

\section{EPIDEMIOLOGY OF ADULT-ONSET ASTHMA}

During the past 20 years, overall asthma prevalence has increased by $38 \%$, in parallel with a similar increase in asthmalike symptoms and allergic rhinitis [43]. Although prevalence rates have been studied more extensively in children, most studies confirm a real increase in asthma prevalence among adults as well. The estimated adult incidence of asthma from pooled general population studies appears to be 4.6 cases per 1,000 person-years in females and 3.6 in males, and there is a trend towards a higher incidence with age [1]. The 5-year ageand sex-specific incidence of newly diagnosed asthma in adults $\geqslant 65$ years of age is estimated to be 103 per 100,000 people, 
where two thirds of asthma deaths occur in people aged $\geqslant 65$ years [44]. Only one study investigated the long-term outcome of adult-onset asthma and changes in asthma severity over time [45]. In this study, $95 \%$ of subjects still had an active asthma 5 years after diagnosis, and half of them had moderateto-severe disease. Due to a relatively low remission rate [45], the prevalence of asthma in older adults ( $\geqslant 65$ years of age) has been reported to be as high as $10 \%$, where females predominate the age group of 64-75 years [35]. Still, these studies probably underestimate the true prevalence and incidence of asthma [46].

\section{RISK FACTORS, TRIGGERS AND CO-MORBID CONDITIONS ASSOCIATED WITH INCIDENT ASTHMA IN ADULTS}

The role of genetic predisposition in adult-onset asthma is less clear than in atopic childhood-onset asthma. In adult-onset asthma, a family history of asthma is often lacking and atopy is not more common than in the general population. One study in a Chinese Han population found an association between genetic variants in chromosome 17q21 and adult-onset asthma, similar to that observed in childhood asthma [17]. Although this study was flawed by the possibility of recall bias in selfreported age of asthma onset, it may point towards similar mechanisms in childhood- and adult-onset asthma, including exposure to environmental triggers such as environmental pollution or infection.

It is difficult to know exactly whether a condition is causally related or just a comorbid condition or a trigger factor. For example, obesity is a comorbid condition but is also a trigger factor for new asthma onset [47]. In the literature, several exogenous and endogenous trigger factors have been associated with the development of asthma in adulthood which will be discussed in the following sections.

\section{Asthma related to sensitising or irritant exposure in the workplace}

Occupational asthma has become the most common type of adult-onset asthma in many industrialised countries, having been implicated in $9-15 \%$ of adult-onset asthma [48]. Two types of occupational asthma have been defined: sensitiser induced (which can be IgE or non-IgE mediated) and irritant induced (i.e. reactive airway syndrome).

Sensitiser-induced asthma is a subtype of occupational asthma typically presenting with a latent period of exposure, followed by the onset of clinical disease. After sensitisation, airway reactions develop from levels of exposure to the sensitising agents that were tolerated before sensitisation. Although the mechanism causing occupational asthma from some sensitisers has been demonstrated to have an immunological basis (IgEmediated or otherwise), the mechanisms for some suspected sensitisers are yet to be defined. There are more than 250 agents that have been adequately documented to cause sensitiser-induced asthma [48]. Some sensitising agents have differential effects on asthma onset depending on the dose. For example, in farmers, exposure to low-dose endotoxins and fungal spores appears to have a protective effect on the development of atopic asthma but may induce non-atopic adult-onset asthma at higher doses [49].
Irritant-induced asthma is a subtype of occupational asthma without immunological sensitisation and includes the typical reactive airways dysfunction syndrome and a more gradual form called not-so-sudden irritant-induced asthma, when asthma follows repeated low-dose exposure to irritants [48]. The World Trade Center tragedy brought new insight in the understanding of irritant-induced asthma, suggesting that it can exhibit a prolonged interval between exposure and recognition of clinical symptoms and disease. A comprehensive review of irritant-induced asthma has been published recently [50].

\section{Environmental pollutants}

Active and passive cigarette smoking is a risk factor for adultonset asthma that is not to be underestimated [51]. A prospective study in patients with allergic rhinitis showed that smoking was significantly related to the risk of incident asthma, with the odds ratio (OR) being 2.67 (95\% CI 1.70-4.19) for univariate and 2.98 (95\% CI 1.81-4.92) for multivariate analyses. A clear dose-response association for exposure to tobacco and risk of new-onset asthma was observed in the multivariate analyses: those with 1-10 pack-years had an OR of 2.05 (95\% CI 0.99-4.27), those with 11-20 pack-years had an OR of 3.71 (95\% CI 1.77-7.78), and those with $\geqslant 21$ pack-years had an OR of 5.05 (95\% CI 1.93-13.20) compared with neversmokers [52]. It is likely that persistent exposure to airborne allergens and cigarette smoking in combination have an additive or synergistic effect.

\section{Female sex hormones}

Female sex hormones are associated with adult-onset asthma [53]. Recently, sex differences in asthma prevalence were investigated in 9,091 males and females randomly selected from the general population and followed for 8-10 years [54]. At baseline, asthma was $20 \%$ more frequent in females than in males over the age of 35 years. The follow-up of subjects without asthma at baseline showed a higher incidence of asthma in females than in males (hazard ratio (HR) 1.94, 95\% CI 1.40-2.68), which was not explained by differences in smoking, obesity or lung function. More than $60 \%$ of females and $30 \%$ of males with new-onset asthma were non-atopic. The incidence of non-allergic asthma was higher in females than in males throughout all the reproductive years (HR $3.51,95 \%$ CI 2.21-5.58), whereas no sex difference was observed for the incidence of allergic asthma. In addition, parity has been shown to be associated with prevalence of asthma from $8 \%$ for one birth to $29 \%$ for four or more births. Alternatively, asthma prevalence decreases with the number of years of oral contraceptive pill use [55]. Likewise, there is evidence that the incidence of asthma is decreased after menopause [56], whereas hormone replacement therapy in post-menopausal females is associated with an increased risk of asthma onset, particularly in never-smokers [57]. Finally, clear associations between puberty and increased incidence of asthma in young females, and a higher remission rate in young males have been described in several reports [14, 58, 59]. These findings suggest that endogenous and exogenous hormonal influences play a role in the genesis of adult-onset asthma in females. Still, associations between asthma and sex hormones remain complex $[60,61]$. 


\section{Upper airway diseases}

Rhinitis is a well-recognised risk factor for the onset of asthma in adulthood [39,62,63]. A role of chronic rhinosinusitis and nasal polyposis in the development of asthma in adulthood has also been suggested, but is less clear. Recently, a large population-based study found a strong association between chronic rhinosinusitis and asthma, where chronic rhinosinusitis in the absence of nasal allergies was positively associated with adult-onset asthma [64]. In turn, adult-onset asthma has been associated with the development of nasal polyps and aspirin intolerance [65]. The mechanisms underlying the relationship between nasal polyposis and adult-onset asthma are poorly understood. Recently, BACHERT et al. [66] found that the presence of IgE against Staphylococcus aureus enterotoxin was associated with more severe upper airways inflammation, as well as comorbid asthma suggesting a causal role for these bacteria in chronic upper and lower airways disease.

\section{Aspirin and paracetamol intake}

Among individuals with existing asthma, aspirin can acutely precipitate bronchospasm in the subset of patients with aspirin-intolerant asthma. In contrast, long-term intake of $100 \mathrm{mg}$ aspirin has been shown to reduce the relative risk of a newly reported diagnosis of asthma in healthy females [67, 68]. Thus, in individuals without asthma, aspirin might reduce the risk of developing asthma via cyclo-oxygenase (COX)-dependent and COX-independent pathways.

On the contrary, the use of paracetamol represents a putative risk factor for the development of asthma [69-71]. Glutathione depletion in the airways and increased oxidative stress may be the mechanism underlying the link between paracetamol use and asthma development.

\section{Respiratory infections}

The occurrence of acute lower respiratory infections is strongly associated with the risk of new adult-onset asthma [72]. The link between respiratory infections and the development of asthma in adulthood has been proposed for many decades [73], although it is still unclear how respiratory infections might induce asthma. Age-related altered antigen presentation and decreased specific antibody responses may lead to subtle immune deficiencies that may allow respiratory infections to provoke injury to the airways. This, in turn, may set up a vicious cycle of an ongoing inflammatory process leading to asthma [74]. Another explanation is that respiratory pathogens may act as triggers of asthma onset to other factors, such as environmental exposures.

Of interest, certain early exposures seem to decrease the risk of asthma in adulthood. A recent study showed that an increased load of common infections in childhood protected against incident asthma risk in adult life, whereas pertussis and measles were associated with an increased risk of incident asthma later in life [75].

\section{Obesity}

Obesity is a risk factor for the development of asthma in adulthood [76]. The incidence of asthma is increased by $50 \%$ in overweight and obese patients [76]. Recently, two observational studies [77, 78] showed that abdominal obesity, assessed by waist circumference, was independently associated with increased prevalence and incidence of asthma. How obesity contributes to asthma development is complicated and there is no single mechanism that supports this association. However, in the literature, several mechanisms have been implicated [79]. First, asthma in obesity is associated with increased adipokines, such as leptin, in visceral adipose tissue. Leptin and other adipokines may have direct effects on the airway rather than enhancing airway inflammation to induce asthma in obesity [80]. Secondly, mechanical factors might be responsible. Obese patients breathe at a lower than normal functional residual capacity which is associated with the risk of both expiratory flow limitation and airway closure and airway hyperresponsiveness. Thus obesity has effects on lung function that can reduce respiratory well-being, even in the absence of specific respiratory disease, and may also exaggerate the effects of existing airway disease [81]. Finally, obesity may increase the risk for asthma onset through its effects on other disease aggravators; for example, sleep-disordered breathing and gastro-oesophageal reflux disease [79]. Since the prevalence of obesity is rapidly increasing, asthma associated with this condition will become a real epidemic in future decades.

\section{Stressful life events}

Stress is increasingly recognised as a risk factor for incident asthma. High versus low stress was found to be associated with a two- to three-fold higher risk of self-reported asthma incidence in several longitudinal population studies [82-85]. Of the 10 most stressful life events, the illness of a family member, marital problems, divorce or separation, and conflicts with a supervisor were most strongly associated with the onset of asthma [82]. Moreover, a study performed by ENG et al. [86] investigated the association between work-related stress and asthma. Participants with very or extremely stressful jobs were $50 \%$ more likely to have adult-onset asthma (OR 1.50, 95\% CI 1.05-2.15). This association was evident for both sexes and was not explained by either occupation, age, body mass index or smoking; although the results did differ by smoking status. Stress has been shown to modulate and activate a number of biological pathways that may be involved in asthma pathophysiology $[87,88]$. It can modulate inflammatory processes via the release of hormones and neuropetides, which have the potential to interact with immune cells. Not only does stress activate the hypothalamic-pituitart-adrenal axis, with subsequent production of cortisol and adrenalin, it may also shift the immune response from an antibacterial T-helper (Th)1 response toward a humoral Th2 response. In this way, stress may alter the psychological, immunological and endocrine systems, and contribute to the onset of asthma.

\section{PHENOTYPES OF ADULT-ONSET ASTHMA}

There are numerous classifications of asthma based on proposed cause (allergic, nonallergic and occupational), pathology (eosinophilic and non-eosinophilic), severity and physiological parameters [89]. To provide a more integrated classification of asthma, taking into account multidimensional parameters, statistical methods such as unsupervised cluster analysis have been used [90]. These clustering techniques have identified several asthma phenotypes distinguished by symptoms and eosinophilic inflammation [3] and by lung function and age of onset [4]. 


\section{Adult-onset obese female preponderant asthma}

This adult-onset asthma phenotype was identified by two independent cluster analysis studies. It was characterised by a predominance of female patients with a higher body mass index (BMI), less atopy and a high symptom expression, in the absence of eosinophilic airway inflammation [3,4]. Despite a shorter duration of asthma, patients in this group had decreased lung function, often reported complicated medical regimens and many of them received regular systemic corticosteroids [4]. These patients' symptoms and healthcare utilisation appeared out of proportion to their degree of airflow obstruction. This suggests an important relationship between obesity, level of symptoms and healthcare utilisation in this adult-onset asthma phenotype.

As described previously, obesity is associated with changes in immune cell function and airway pathology, which are likely to lead to new onset disease in individuals without pre-existing asthma [91]. Patients with childhood-onset asthma are less affected by obesity, indicating that obesity is primarily associated with the adult-onset asthma phenotype [92]. A recent study confirmed that obese patients have more severe clinical expression of their asthma [93]. In this study, greater asthma medication requirements, steroid-burst therapy and shortacting $\beta_{2}$-agonist use per day were found in these obese patients with severe asthma. In addition, increased gastro-oesophageal reflux disease and increased proton-pump inhibitor use were seen in the obese group. Given the fact that obese patients with severe asthma do not exhibit more severe eosinophilic airway inflammation [94] than those without obesity, the primary treatment should consist of weight reduction, rather than stepping up anti-inflammatory treatment [95].

\section{Adult-onset nonatopic, inflammation-predominant phenotype with fixed airflow limitation}

The most severe adult-onset asthma phenotype that was identified by one of the cluster analyses comprised mainly of males with few daily symptoms and active eosinophilic airway inflammation [3]. Persistent sputum eosinophilia, the key characteristics of this phenotype, has important clinical implications since it is associated with frequent asthma exacerbations [96], persistent airflow limitation [41] and oral corticosteroid dependence [97]. Moreover, this phenotype is associated with chronic rhinosinusitis, nasal polyps [98] and aspirin sensitivity [99]. The eosinophilic asthma phenotype with severe sinus disease has also been shown to have more air trapping and reduced diffusion capacity, suggestive of more peripheral airway inflammation [100].

Since eosinophilis seem to play a key role in the pathophysiology of this adult-onset asthma phenotype, drugs that inhibit recruitment and activation of eosinophilis might be particularly efficacious. Recent large-scale studies with anti-interleukin (IL)-5 therapy suggest that this is indeed the case [101].

\section{Adult-onset mild asthma}

In addition to the two phenotypes with severe adult-onset asthma, a recent cluster analysis in 724 Korean patients with asthma also identified a milder adult-onset asthma phenotype [102]. This cluster covered one-third of the total asthma population and had the best lung function. $74 \%$ of these patients were female, $54 \%$ were atopic, none of them had a significant smoking history, BMI in these patients was low, and there were no other characteristics that distinguished them from the other clusters. As in this study there were no data on asthma duration, this milder asthma phenotype might have represented recent or even transient cases of adult-onset asthma. Apparently, adult-onset asthma is not always severe and can have a milder clinical course and prognosis as well.

\section{Smoking-related asthma}

In the same Korean cluster analysis study, a separate phenotype of adult-onset smoking-related asthma was identified [102]. This cluster mainly consisted of male patients with a mean age of asthma onset of 46 years. About $66 \%$ of the patients were non-atopic and this group had a relatively well preserved FEV1. Although cigarette smoking is known to increase the risk of incident asthma [52], the smoking asthma phenotype has not been identified in other cluster analysis studies to date. This is probably due to the fact that smokers and ex-smokers with a smoking history of $>5$ pack-years were not included in these studies. It would be worthwhile to redo these cluster analyses after inclusion of smoking asthmatics and by taking markers of airway inflammation into account.

In summary, the identification of specific, clinically wellrecognised adult-onset asthma phenotypes by cluster analysis is the first step to better understand the mechanisms of asthma development in adulthood. The next step will be to refine the characteristics of these phenotypes adding well-known aetiological factors such as occupational exposure, nasal polyposis and aspirin sensitivity into the models. Furthermore, the stability of the asthma phenotypes has to be further explored [103]. In children, the clinical expression of the disease varies over time and novel wheezing phenotypes have been identified on the basis of longitudinal follow-up data [104]. Whether specific longitudinal phenotypic patterns also exist in adult-onset asthma is currently unknown.

\section{PHENOTYPES VERSUS "ENDOTYPES"}

While phenotypes are usually clinically relevant in terms of presentation, triggers and treatment response, they do not necessarily relate to or give any insight into the underlying disease processes. An endotype is a subtype of a disease that is defined by a distinct functional or pathobiological mechanism [105]. Until now, such endotypes have not been identified, although some investigators have proposed a few asthma endotypes on the basis of their clinical phenotypes and putative pathophysiology [106]. However, at present, there is no evidence that these proposed endotypes are defined by specific molecular pathways. More advanced approaches, such as systems biology relying on multiple disciplines including genomic, proteomic and metabolomics, are therefore needed to understand mechanisms and identify the real asthma endotypes.

\section{Phenotype-driven treatment of adult-onset asthma}

In childhood-onset allergic asthma, daily therapy with inhaled corticosteroids combined with long-acting $\beta_{2}$-agonists is effective in improving asthma control in the vast majority of patients [33]. In adult-onset asthma, a large proportion of patients respond poorly to corticosteroid therapy [3, 4]. Given the heterogeneity of causative factors, this group of patients might benefit from a more targeted, phenotype-driven treatment [107]. 
For example, for some patients, prevention of exposure to the proposed cause (occupational sensitisers and smoking) is the best treatment option. In other patients, discontinuation of specific drugs such as hormonal preparations might be most beneficial. In addition, with regard to novel treatments, there are now exciting possibilities for a more targeted, phenotypic approach.

\section{Omalizumab}

Omalizumab, a humanised antibody against IgE, was originally designed as a therapeutic option for severe allergic asthma. This drug has been shown to effectively reduce asthma exacerbations, emergency visits for asthma and hospitalisation admissions among children and adults with allergic asthma [108-112]. Recent studies, however, also showed a positive effect on nonallergic asthma [113,114] and on nasal polyps [113], suggesting that this drug might be effective in specific subtypes of adultonset asthma as well. However, before the indication of omalizumab can be broadened, further large prospective clinical trials need to be conducted.

\section{Mepolizumab}

A novel, promising strategy to treat patients with adult-onset asthma who have persistent eosinophilia is to target the eosinophil itself. Mepolizumab, a humanised monoclonal antibody against IL-5, selectively and effectively inhibits eosinophilic airway inflammation. Recently, PAVORD et al. [101] provided evidence for mepolizumab as an effective, well tolerated and safe treatment that reduces the risk of asthma exacerbations in patients with severe eosinophilic asthma. A previous smaller scale study showed that mepolizumab allows a reduction of the oral corticosteroid dose in patients with corticosteroid-dependent eosinophilic asthma. Interestingly, a recent study showed that mepolizumab is also effective in the treatment of severe nasal polyposis [115]. All these studies are very promising for patients with severe adult onset asthma characterised by eosinophilic inflammation for whom no effective drugs are available without significant adverse effects.

\section{Lebrikizumab}

Another drug that might be effective in severe adult-onset eosinophilic asthma is lebrikizumab. Lebrikizumab is a humanised monoclonal antibody that binds to IL-13. A recent study reported the effects of lebrikizumab in a cohort of patients with moderate asthma who were symptomatic despite taking inhaled glucosteroids and, in most cases, an additional long-acting $\beta$-agonist [116]. Although there was an effect on airflow limitation in all the patients who were treated with lebrikizumab, the effect was greater in patients who had circulating levels of periostin above the median and exhibited the high Th2 phenotype than those without this phenotype. These data confirm the proof of concept that asthma therapy can be targeted to specific asthma phenotypes.

\section{Bronchial thermoplasty}

Bronchial thermoplasty is a bronchoscopic procedure that is approved for the treatment of severe asthma. In non-obese patients with adult-onset non-eosinophilic severe asthma, this might be one of the only effective therapeutic options. During this procedure, controlled thermal energy is applied to the airway wall to decrease the amount of smooth muscle [117].
Studies suggest that this intervention could improve lung function, airways hyperresponsiveness, asthma-related quality of life and symptom scores, and reduce exacerbations and hospitalisations [118-120]. Thermoplasty has been proven safe in the long run, without long-term complications and maintenance of stable lung function [121]. Therefore, thermoplasty might be an option for some patients with adult-onset asthma, but this has to be confirmed in large-scale prospective studies.

\section{Bariatric surgery}

For the obese adult non-eosinophilic asthma phenotype, there is currently only one treatment option, which is drastic weight reduction. A study using bariatric surgery showed that this treatment can markedly improve asthma control [95]. Bariatric surgery was performed in 23 asthmatic and 21 nonasthmatic patients. After surgery, asthmatic patients experienced improvements in asthma control and asthma quality of life. Moreover, airway hyperresponsiveness to methacholine improved in obese asthmatic patients with normal serum IgE levels [95]. Several large trials are now underway to confirm the beneficial effect of bariatric surgery on asthma control and airway hyperresponsiveness.

\section{CONCLUSION}

Compared to childhood-onset asthma, adult-onset asthma has worse prognosis and poorer response to standard asthma treatment. Many risk factors responsible for the onset of asthma in adulthood have been recognised, varying from respiratory infections to environmental sensitisers, hormonal factors, obesity and stress. Recently, cluster analysis identified specific and clinically well-recognised adult-onset asthma phenotypes and, consequently, new exciting possibilities have been developed for a more targeted, phenotypic approached in patients with adult-onset asthma. Still, the underlying pathophysiological mechanisms of asthma severity and poor clinical outcome are largely uninvestigated. A better understanding of key biological pathways by using systems medicine approaches will not only help to prevent the development of asthma in adulthood but will certainly lead to better targeted treatments. Therefore, large scale prospective follow-up studies of patients with adult-onset asthma are urgently needed, especially in those who are in an early stage of their disease.

\section{STATEMENT OF INTEREST}

E.H. Bel has received, on behalf of the Department of Respiratory Medicine of the Academic Medical Centre, grant monies from GSK, Novartis and Chiesi; consultancy fees from Actelion, Merck, Schering Plough and GSK; and fees for speaking from GSK, Novartis and Nycomed.

\section{REFERENCES}

1 Eagan TM, Brogger JC, Eide GE, et al. The incidence of adult asthma: a review. Int J Tuberc Lung Dis 2005; 9: 603-612.

2 Masoli M, Fabian D, Holt S, et al. The global burden of asthma: executive summary of the GINA Dissemination Committee report. Allergy 2004; 59: 469-478.

3 Haldar P, Pavord ID, Shaw DE, et al. Cluster analysis and clinical asthma phenotypes. Am J Respir Crit Care Med 2008; 178: 218-224.

4 Moore WC, Meyers DA, Wenzel SE, et al. Identification of asthma phenotypes using cluster analysis in the Severe Asthma Research Program. Am J Respir Crit Care Med 2010; 181: 315-323. 
5 ten Brinke A, van Dissel JT, Sterk PJ, et al. Persistent airflow limitation in adult-onset nonatopic asthma is associated with serologic evidence of Chlamydia pneumoniae infection. J Allergy Clin Immunol 2001; 107: 449-454.

6 Ulrik CS, Lange P. Decline of lung function in adults with bronchial asthma. Am J Respir Crit Care Med 1994; 150: 629-634.

7 Bush A, Menzies-Gow A. Phenotypic differences between pediatric and adult asthma. Proc Am Thorac Soc 2009; 6: 712-719.

8 Rackemann FM. Intrinsic asthma. J Allergy 1940; 11: 147.

9 Johansson SG, Hourihane JO, Bousquet J, et al. A revised nomenclature for allergy. An EAACI position statement from the EAACI nomenclature task force. Allergy 2001; 56: 813-824.

10 Humbert M, Menz G, Ying S, et al. The immunopathology of extrinsic (atopic) and intrinsic (non-atopic) asthma: more similarities than differences. Immunol Today 1999; 20: 528-533.

11 Romanet-Manent S, Charpin D, Magnan A, et al. Allergic vs nonallergic asthma: what makes the difference? Allergy 2002; 57: 607-613.

12 Miranda C, Busacker A, Balzar S, et al. Distinguishing severe asthma phenotypes: role of age at onset and eosinophilic inflammation. J Allergy Clin Immunol 2004; 113: 101-108.

13 Almqvist C, Worm M, Leynaert B. Impact of gender on asthma in childhood and adolescence: a GA ${ }^{2} \mathrm{LEN}$ review. Allergy 2008; 63: 47-57.

14 Vink NM, Postma DS, Schouten JP, et al. Gender differences in asthma development and remission during transition through puberty: the TRacking Adolescents' Individual Lives Survey (TRAILS) study. J Allergy Clin Immunol 2010; 126: 498-504.

15 Bisgaard H, Bonnelykke K. Long-term studies of the natural history of asthma in childhood. J Allergy Clin Immunol 2010; 126: 187-197.

16 Bray GW. The hereditary factor in asthma and other allergies. $\mathrm{Br}$ Med J 1930; 1: 384-387.

17 Moffatt MF, Gut IG, Demenais F, et al. A large-scale, consortiumbased genomewide association study of asthma. $N$ Engl J Med 2010; 363: 1211-1221.

18 Bouzigon E, Corda E, Aschard H, et al. Effect of 17q21 variants and smoking exposure in early-onset asthma. N Engl J Med 2008; 359: 1985-1994.

19 Lau S, Illi S, Sommerfeld C, et al. Early exposure to house-dust mite and cat allergens and development of childhood asthma: a cohort study. Multicentre Allergy Study Group. Lancet 2000; 356: 1392-1397.

20 Rochat MK, Illi S, Ege MJ, et al. Allergic rhinitis as a predictor for wheezing onset in school-aged children. J Allergy Clin Immunol 2010; 126: 1170-1175.

21 Wu P, Dupont WD, Griffin MR, et al. Evidence of a causal role of winter virus infection during infancy in early childhood asthma. Am J Respir Crit Care Med 2008; 178: 1123-1129.

22 Jackson DJ, Gangnon RE, Evans MD, et al. Wheezing rhinovirus illnesses in early life predict asthma development in high-risk children. Am J Respir Crit Care Med 2008; 178: 667-672.

23 Lemanske RF Jr, Jackson DJ, Gangnon RE, et al. Rhinovirus illnesses during infancy predict subsequent childhood wheezing. J Allergy Clin Immunol 2005; 116: 571-577.

24 Goetghebuer T, Kwiatkowski D, Thomson A, et al. Familial susceptibility to severe respiratory infection in early life. Pediatr Pulmonol 2004; 38: 321-328.

25 Stensballe LG, Kristensen K, Simoes EA, et al. Atopic disposition, wheezing, and subsequent respiratory syncytial virus hospitalization in Danish children younger than 18 months: a nested casecontrol study. Pediatrics 2006; 118: e1360-e1368.

26 Trefny P, Stricker T, Baerlocher C, et al. Family history of atopy and clinical course of RSV infection in ambulatory and hospitalized infants. Pediatr Pulmonol 2000; 30: 302-306.

27 Bisgaard H, Hermansen MN, Buchvald F, et al. Childhood asthma after bacterial colonization of the airway in neonates. N Engl J Med 2007; 357: 1487-1495.
28 Ege MJ, Mayer M, Normand AC, et al. Exposure to environmental microorganisms and childhood asthma. $N$ Engl J Med 2011; 364: 701-709.

29 Omland $\mathrm{O}$, Hjort C, Pedersen OF, et al. New-onset asthma and the effect of environment and occupation among farming and nonfarming rural subjects. J Allergy Clin Immunol 2011; 128: 761-765.

30 Varraso R, Oryszczyn MP, Mathieu N, et al. Farming in childhood, diet in adulthood and asthma history. Eur Respir J 2012; 39: 67-75.

31 Burke H, Leonardi-Bee J, Hashim A, et al. Prenatal and passive smoke exposure and incidence of asthma and wheeze: systematic review and meta-analysis. Pediatrics 2012; 129: 735-744.

32 Gehring U, Wijga AH, Brauer M, et al. Traffic-related air pollution and the development of asthma and allergies during the first 8 years of life. Am J Respir Crit Care Med 2010; 181: 596-603.

33 Kaditis AG, Winnie G, Syrogiannopoulos GA. Anti-inflammatory pharmacotherapy for wheezing in preschool children. Pediatr Pulmonol 2007; 42: 407-420.

34 Castro-Rodriguez JA, Rodrigo GJ. Efficacy of inhaled corticosteroids in infants and preschoolers with recurrent wheezing and asthma: a systematic review with meta-analysis. Pediatrics 2009; 123: e519-e525.

35 Gibson PG, McDonald VM, Marks GB. Asthma in older adults. Lancet 2010; 376: 803-813.

36 Stern DA, Morgan WJ, Halonen M, et al. Wheezing and bronchial hyper-responsiveness in early childhood as predictors of newly diagnosed asthma in early adulthood: a longitudinal birth-cohort study. Lancet 2008; 372: 1058-1064.

37 Toren K, Palmqvist M, Lowhagen O, et al. Self-reported asthma was biased in relation to disease severity while reported year of asthma onset was accurate. J Clin Epidemiol 2006; 59: 90-93.

38 de Marco R, Locatelli F, Cerveri I, et al. Incidence and remission of asthma: a retrospective study on the natural history of asthma in Italy. J Allergy Clin Immunol 2002; 110: 228-235.

39 Shaaban R, Zureik M, Soussan D, et al. Rhinitis and onset of asthma: a longitudinal population-based study. Lancet 2008; 372: 1049-1057.

40 Amelink M, de Nijs SB, Berger M, et al. Non-atopic males with adult onset asthma are at risk of persistent airflow limitation. Clin Exp Allergy 2012; 42: 769-774.

41 ten Brinke A, Zwinderman AH, Sterk PJ, et al. Factors associated with persistent airflow limitation in severe asthma. Am J Respir Crit Care Med 2001; 164: 744-748.

42 Jenkins HA, Cherniack R, Szefler SJ, et al. A comparison of the clinical characteristics of children and adults with severe asthma. Chest 2003; 124: 1318-1324.

43 de Marco R, Cappa V, Accordini S, et al. Trends in the prevalence of asthma and allergic rhinitis in Italy between 1991 and 2010. Eur Respir J 2012; 39: 883-892.

44 Bauer BA, Reed CE, Yunginger JW, et al. Incidence and outcomes of asthma in the elderly. A population-based study in Rochester, Minnesota. Chest 1997; 111: 303-310.

45 Ronmark E, Lindberg A, Watson L, et al. Outcome and severity of adult onset asthma - report from the obstructive lung disease in northern Sweden studies (OLIN). Respir Med 2007; 101: 2370-2377.

46 Enright PL, McClelland RL, Newman AB, et al. Underdiagnosis and undertreatment of asthma in the elderly. Cardiovascular Health Study Research Group. Chest 1999; 116: 603-613.

47 Holguin F. Obesity as a risk factor for increased asthma severity and allergic inflammation; cause or effect? Clin Exp Allergy 2012; 42: 612-613.

48 Dykewicz MS. Occupational asthma: current concepts in pathogenesis, diagnosis, and management. J Allergy Clin Immunol 2009; 123: 519-528.

49 Eduard W, Douwes J, Omenaas E, et al. Do farming exposures cause or prevent asthma? Results from a study of adult Norwegian farmers. Thorax 2004; 59: 381-386. 
50 Labrecque M. Irritant-induced asthma. Curr Opin Allergy Clin Immunol 2012; 12: 140-144.

51 Strachan DP, Butland BK, Anderson HR. Incidence and prognosis of asthma and wheezing illness from early childhood to age 33 in a national British cohort. BMJ 1996; 312: 1195-1199.

52 Polosa R, Knoke JD, Russo C, et al. Cigarette smoking is associated with a greater risk of incident asthma in allergic rhinitis. J Allergy Clin Immunol 2008; 121: 1428-1434.

53 Melgert BN, Ray A, Hylkema MN, et al. Are there reasons why adult asthma is more common in females? Curr Allergy Asthma Rep 2007; 7: 143-150.

54 Leynaert B, Sunyer J, Garcia-Esteban R, et al. Gender differences in prevalence, diagnosis and incidence of allergic and non-allergic asthma: a population-based cohort. Thorax 2012; 67: 625-631.

55 Jenkins MA, Dharmage SC, Flander LB, et al. Parity and decreased use of oral contraceptives as predictors of asthma in young women. Clin Exp Allergy 2006; 36: 609-613.

56 Troisi RJ, Speizer FE, Willett WC, et al. Menopause, postmenopausal estrogen preparations, and the risk of adult-onset asthma. A prospective cohort study. Am J Respir Crit Care Med 1995; 152: 1183-1188.

57 Romieu I, Fabre A, Fournier A, et al. Postmenopausal hormone therapy and asthma onset in the E3N cohort. Thorax 2010; 65 292-297.

58 Al-Sahab B, Hamadeh MJ, Ardern CI, et al. Early menarche predicts incidence of asthma in early adulthood. Am J Epidemiol 2011; 173: 64-70.

59 Salam MT, Wenten M, Gilliland FD. Endogenous and exogenous sex steroid hormones and asthma and wheeze in young women. J Allergy Clin Immunol 2006; 117: 1001-1007.

60 Haggerty CL, Ness RB, Kelsey S, et al. The impact of estrogen and progesterone on asthma. Ann Allergy Asthma Immunol 2003; 90: 284-291.

61 van den Berge M, Heijink HI, van Oosterhout $\mathrm{AJ}$, et al. The role of female sex hormones in the development and severity of allergic and non-allergic asthma. Clin Exp Allergy 2009; 39: 1477-1481.

62 Guerra S, Sherrill DL, Martinez FD, et al. Rhinitis as an independent risk factor for adult-onset asthma. J Allergy Clin Immunol 2002; 109: 419-425.

63 Toren K, Olin AC, Hellgren J, et al. Rhinitis increase the risk for adult-onset asthma - a Swedish population-based case-control study (MAP-study). Respir Med 2002; 96: 635-641.

64 Jarvis D, Newson R, Lotvall J, et al. Asthma in adults and its association with chronic rhinosinusitis: the $\mathrm{GA}^{2} \mathrm{LEN}$ survey in Europe. Allergy 2012; 67: 91-98.

65 Fokkens WJ, Lund VJ, Mullol J, et al. European position paper on rhinosinusitis and nasal polyps 2012. Rhinol Suppl 2012; 50: Suppl. 23, 3-298.

66 Bachert C, Zhang N, Holtappels G, et al. Presence of IL-5 protein and $\operatorname{IgE}$ antibodies to staphylococcal enterotoxins in nasal polyps is associated with comorbid asthma. J Allergy Clin Immunol 2010; 126: 962-968.

67 Barr RG, Kurth T, Stampfer MJ, et al. Aspirin and decreased adult-onset asthma: randomized comparisons from the physicians' health study. Am J Respir Crit Care Med 2007; 175: 120-125.

68 Kurth T, Barr RG, Gaziano JM, et al. Randomised aspirin assignment and risk of adult-onset asthma in the Women's Health Study. Thorax 2008; 63: 514-518.

69 Barr RG, Wentowski CC, Curhan GC, et al. Prospective study of acetaminophen use and newly diagnosed asthma among women. Am J Respir Crit Care Med 2004; 169: 836-841.

70 Shaheen S, Potts J, Gnatiuc L, et al. The relation between paracetamol use and asthma: a GA ${ }^{2}$ LEN European case-control study. Eur Respir J 2008; 32: 1231-1236.

71 Thomsen SF, Kyvik KO, Skadhauge L, et al. Intake of paracetamol and risk of asthma in adults. J Asthma 2008; 45: 675-676.
72 Rantala A, Jaakkola JJ, Jaakkola MS. Respiratory infections precede adult-onset asthma. PLoS One 2011; 6: e27912.

73 Rackemann FM, Mallory TB. Intrinsic Asthma. Trans Am Clin Climatol Assoc 1941; 57: 60-73.

74 Dahlberg PE, Busse WW. Is intrinsic asthma synonymous with infection? Clin Exp Allergy 2009; 39: 1324-1329.

75 Burgess JA, Abramson MJ, Gurrin LC, et al. Childhood infections and the risk of asthma: a longitudinal study over 37 years. Chest 2012; 142: 647-654.

76 Beuther DA, Sutherland ER. Overweight, obesity, and incident asthma: a meta-analysis of prospective epidemiologic studies. Am J Respir Crit Care Med 2007; 175: 661-666.

77 Brumpton B, Langhammer A, Romundstad P, et al. General and abdominal obesity and incident asthma in adults: the HUNT study. Eur Respir J 2013; 41: 323-329.

78 Leone N, Courbon D, Berr C, et al. Abdominal obesity and lateonset asthma: cross-sectional and longitudinal results: the $3 \mathrm{C}$ study. Obesity (Silver Spring) 2012; 20: 628-635.

79 Shore SA. Obesity and asthma: possible mechanisms. J Allergy Clin Immunol 2008; 121: 1087-1093.

80 Sideleva O, Suratt BT, Black KE, et al. Obesity and asthma: an inflammatory disease of adipose tissue not the airway. $A m \mathrm{~J}$ Respir Crit Care Med 2012; 186: 598-605.

81 Salome CM, King GG, Berend N. Physiology of obesity and effects on lung function. J Appl Physiol 2010; 108: 206-211.

82 Lietzen R, Virtanen P, Kivimaki M, et al. Stressful life events and the onset of asthma. Eur Respir J 2011; 37: 1360-1365.

83 Loerbroks A, Gadinger MC, Bosch JA, et al. Work-related stress, inability to relax after work and risk of adult asthma: a population-based cohort study. Allergy 2010; 65: 1298-1305.

84 Rod NH, Kristensen TS, Lange P, et al. Perceived stress and risk of adult-onset asthma and other atopic disorders: a longitudinal cohort study. Allergy 2012; 67: 1408-1414.

85 Wright RJ, Fay ME, Suglia SF, et al. War-related stressors are associated with asthma risk among older Kuwaitis following the 1990 Iraqi invasion and occupation. J Epidemiol Community Health 2010; 64: 630-635.

86 Eng A, Mannetje A, Pearce N, et al. Work-related stress and asthma: results from a workforce survey in New Zealand. J Asthma 2011; 48: 783-789.

87 Elenkov IJ, Chrousos GP. Stress hormones, Th1/Th2 patterns, pro/anti-inflammatory cytokines and susceptibility to Disease. Trends Endocrinol Metab 1999; 10: 359-368.

88 Vink NM, Marike Boezen H, Postma DS, et al. Basal or stressinduced cortisol and asthma development. The TRAILS study. Eur Respir J 2012 [Epub ahead of print DOI: 10.1183/ 09031936.00021212].

89 Green $\mathrm{RH}$, Brightling CE, Bradding P. The reclassification of asthma based on subphenotypes. Curr Opin Allergy Clin Immunol 2007; 7: 43-50.

90 Weatherall M, Shirtcliffe $\mathrm{P}$, Travers J, et al. Use of cluster analysis to define COPD phenotypes. Eur Respir J 2010; 36: 472-474.

91 Sideleva O, Black K, Dixon AE. Effects of obesity and weight loss on airway physiology and inflammation in asthma. Pulm Pharmacol Ther 2012 [Epub ahead of print DOI: 10.1016/ j.pupt.2012.05.002].

92 Holguin F, Bleecker ER, Busse WW, et al. Obesity and asthma: an association modified by age of asthma onset. J Allergy Clin Immunol 2011; 127: 1486-1493.

93 Gibeon D, Batuwita R, Osmond M, et al. Obesity associated severe asthma represents a distinct clinical phenotype - Analysis of the British Thoracic Society difficult asthma registry patient cohort according to body mass index. Chest 2012 [Epub ahead of print DOI: 10.1378/chest.12-0872]

94 van Veen $\mathrm{IH}$, ten Brinke A, Sterk PJ, et al. Airway inflammation in obese and nonobese patients with difficult-to-treat asthma. Allergy 2008; 63: 570-574. 
95 Dixon AE, Pratley RE, Forgione PM, et al. Effects of obesity and bariatric surgery on airway hyperresponsiveness, asthma control, and inflammation. J Allergy Clin Immunol 2011; 128: 508-515.

96 Green RH, Brightling CE, McKenna S, et al. Asthma exacerbations and sputum eosinophil counts: a randomised controlled trial. Lancet 2002; 360: 1715-1721.

97 ten Brinke A, Zwinderman AH, Sterk PJ, et al. "Refractory" eosinophilic airway inflammation in severe asthma: effect of parenteral corticosteroids. Am J Respir Crit Care Med 2004; 170: 601-605.

98 van Veen IH, ten BA, Gauw SA, et al. Consistency of sputum eosinophilia in difficult-to-treat asthma: a 5-year follow-up study. J Allergy Clin Immunol 2009; 124: 615-617.

99 Szczeklik A, Stevenson DD. Aspirin-induced asthma: advances in pathogenesis, diagnosis, and management. J Allergy Clin Immunol 2003; 111: 913-921.

100 ten Brinke A, Grootendorst DC, Schmidt JT, et al. Chronic sinusitis in severe asthma is related to sputum eosinophilia. J Allergy Clin Immunol 2002; 109: 621-626.

101 Pavord ID, Korn S, Howarth P, et al. Mepolizumab for severe eosinophilic asthma (DREAM): a multicentre, double-blind, placebo-controlled trial. Lancet 2012; 380: 651-659.

102 Kim TB, Jang AS, Kwon HS, et al. Identification of asthma clusters in two independent Korean adult asthma cohorts. Eur Respir J 2012 [Epub ahead of print DOI: 10.1183/ 09031936.00100811].

103 Siroux V, Garcia-Aymerich J. The investigation of asthma phenotypes. Curr Opin Allergy Clin Immunol 2011; 11: 393-399.

104 Savenije OE, Granell R, Caudri D, et al. Comparison of childhood wheezing phenotypes in 2 birth cohorts: ALSPAC and PIAMA. J Allergy Clin Immunol 2011; 127: 1505-1512.

105 Anderson GP. Endotyping asthma: new insights into key pathogenic mechanisms in a complex, heterogeneous disease. Lancet 2008; 372: 1107-1119.

106 Lotvall J, Akdis CA, Bacharier LB, et al. Asthma endotypes: a new approach to classification of disease entities within the asthma syndrome. J Allergy Clin Immunol 2011; 127: 355-360.

107 Wenzel SE. Asthma phenotypes: the evolution from clinical to molecular approaches. Nat Med 2012; 18: 716-725.

108 Busse WW, Morgan WJ, Gergen PJ, et al. Randomized trial of omalizumab (anti-IgE) for asthma in inner-city children. N Engl J Med 2011; 364: 1005-1015.
109 Corren J, Casale T, Deniz Y, et al. Omalizumab, a recombinant humanized anti-IgE antibody, reduces asthma-related emergency room visits and hospitalizations in patients with allergic asthma. J Allergy Clin Immunol 2003; 111: 87-90.

110 Hanania NA, Alpan O, Hamilos DL, et al. Omalizumab in severe allergic asthma inadequately controlled with standard therapy: a randomized trial. Ann Intern Med 2011; 154: 573-582.

111 Lanier B, Bridges $\mathrm{T}$, Kulus $\mathrm{M}$, et al. Omalizumab for the treatment of exacerbations in children with inadequately controlled allergic (IgE-mediated) asthma. J Allergy Clin Immunol 2009; 124: 1210-1216.

112 Niven R, Chung KF, Panahloo Z, et al. Effectiveness of omalizumab in patients with inadequately controlled severe persistent allergic asthma: an open-label study. Respir Med 2008; 102: $1371-1378$

113 Gevaert P, Calus L, Van Zele T, et al. Omalizumab is effective in allergic and nonallergic patients with nasal polyps and asthma. J Allergy Clin Immunol 2013; 131: 110-116.

114 van den Berge M, Pauw RG, de Monchy JG, et al. Beneficial effects of treatment with anti-IgE antibodies (Omalizumab) in a patient with severe asthma and negative skin-prick test results. Chest 2011; 139: 190-193.

115 Gevaert P, Van Bruaene N, Cattaert T, et al. Mepolizumab, a humanized anti-IL-5 mAb, as a treatment option for severe nasal polyposis. J Allergy Clin Immunol 2011; 128: 989-995.

116 Corren J, Lemanske RF, Hanania NA, et al. Lebrikizumab treatment in adults with asthma. N Engl J Med 2011; 365: 1088-1098.

117 Cox PG, Miller J, Mitzner W, et al. Radiofrequency ablation of airway smooth muscle for sustained treatment of asthma: preliminary investigations. Eur Respir J 2004; 24: 659-663.

118 Castro M, Rubin AS, Laviolette M, et al. Effectiveness and safety of bronchial thermoplasty in the treatment of severe asthma: a multicenter, randomized, double-blind, sham-controlled clinical trial. Am J Respir Crit Care Med 2010; 181: 116-124.

119 Cox G, Thomson NC, Rubin AS, et al. Asthma control during the year after bronchial thermoplasty. N Engl J Med 2007; 356: 1327-1337.

120 Cox G, Miller JD, McWilliams A, et al. Bronchial thermoplasty for asthma. Am J Respir Crit Care Med 2006; 173: 965-969.

121 Thomson NC, Rubin AS, Niven RM, et al. Long-term (5 year) safety of bronchial thermoplasty: Asthma Intervention Research (AIR) trial. BMC Pulm Med 2011; 11: 8. 